\title{
ROLE OF TISSUE DOPPLER ECHOCARDIOGRAPHY IN THE DIAGNOSIS OF EARLY LEFT VENTRICULAR DYSFUNCTION IN RHEUMATOID ARTHRITIS
}

\author{
Ashok Arigondam, Vara Prasad, Liza Rajasekhar
}

\begin{abstract}
Objective: Rheumatoid arthritis (RA) is a systemic disease involving many organ systems and is frequently accompanied by cardiac alterations. The purpose of our study is the usefulness of Tissue Doppler echocardiography to detect the nature and extent of cardiac involvement in RA patients with no symptoms of cardiac disease, in comparison with a control sample.

Methods: We selected 21 patients affected by rheumatoid arthritis. No patient had any symptoms of cardiac disease. As a control group we studied 21 volunteers, randomly selected among a larger group of subjects who had come for routine check-up. All were in sinus rhythm and without any cardiac symptom. Standard two-dimensional, M-mode and Doppler echocardiographic examination was carried out on each subject.

Results: out of 21 RA patients, 16 females 5 males with an average age of $38 \pm 9$ years. Both the study group and control were matched with respect to age and sex. In RA patients we found a higher prevalence of several tissue Doppler parameters abnormalities. Patients with RA showed significantly higher

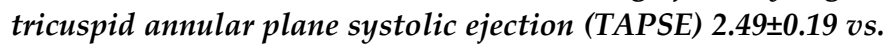
$2.36 \pm 0.22(p=0.04)$, isovolumetric contraction time (IVCT) $48.8 \pm 11.7$ vs. $41.2 \pm 7.7 \mathrm{msec}$, $(p=0.02)$, isovolumetric velocity (IVV) $12.26 \pm 2.23$ vs. $15.71 \pm 1.89 \mathrm{~m} / \mathrm{sec}(p=0.00)$ acceleration time (AT) $0.43 \pm 0.05$ vs. $0.35+0.05 \mathrm{msec}(p=0.00)$ lower isovolumetric acceleration (IVA) $28.68 \pm 6.57$ vs. $45.8 \pm 10.1$ $m / \mathrm{sec} 2(p=0.00)$ early diastolic velocity $(E)^{\prime} 10.48 \pm 1.99$ vs. $13.02 \pm 1.54 \mathrm{~cm} / \mathrm{sec}(p=0.00)$. No significant difference was noted with IVRT (isovolumetric relaxation time) and $A^{\prime}$ (late diastolic velocity). Duration of RA did not affect the significance of these parameters.

Conclusion: There was subclinical LV systolic and diastolic dysfunction with normal EF, detected by tissue Doppler imaging in Rheumatoid arthritis patients.

Key words: Rheumatoid arthritis, diastolic dysfunction, Tissue Doppler echocardiography

Ashok Arigondam ${ }^{1}$, Vara Prasad ${ }^{2}$, Liza Rajasekhar ${ }^{3}$

${ }^{1}$ DM 2nd year student, Department of Cardiology, Nizam's Institute of Medical Sciences, India.

${ }^{2}$ Associate Prof, Department of rheumatology

${ }^{3}$ Professor \& Head, Department of Rheumatology

Corresponding author: Ashok Arigondam1

Email: ashokari@gmail.com
\end{abstract}

\section{INTRODUCTION}

Rheumatoid arthritis (RA) is the most common systemic autoimmune disease. Long-term survival of patients with RA is shorter compared with that of the general population [1]. Several studies have documented increased morbidity and mortality among people with RA and cardiac disease is one important etiology behind it. However, cardiac disease is often clinically silent and is rarely a severe life threatening complication in RA. Necropsy studies showed a high incidence of pericardial, myocardial, and endocardium involvement in RA patients [2]. Cardiac failure in RAis the result of either systolic or diastolic dysfunction, or both. Left ventricular (LV) diastolic dysfunction is usually attributable to common structural abnormalities such as hypertrophy or interstitial fibrosis and impaired myocyte relaxation resulting from ischemia.

A number of non invasive techniques like Doppler echocardiography, color Doppler M-mode, tissue Doppler imaging (TDI), magnetic resonance imaging, and radionuclide ventriculography can be used for the evaluation of LV diastolic functions [3]. The technique used most often among these is Doppler echocardiography. Because mitral flow velocity detected by Doppler echocardiography is affected by many factors like heart rate, preload, and afterload, new Doppler parameters were developed to overcome these limitations in the evaluation of mitral flow diastolic functions [4]. One of these is tissue Doppler imaging. Studies reveal that diastolic velocity detected with TDI is preload-independent and it can be used with reasonable accuracy in patients with tachycardia. At present there are a number of studies evaluating diastolic functions with conventional Doppler in RA patients. However a study related to the use of TDI providing better information about diastolic functions in RA is scanty in literature.

The purpose of our study was to determine nature and extent of cardiac involvement in patients with RA in 
comparison with a control group sample by a noninvasive method such as TDI technique in addition to conventional Doppler, in active RA patients without apparent cardiovascular disease, with special regard to disease duration.

\section{MATERIALS AND METHODS:}

Subject selection and study procedure: A total of 21 subjects constituted our study. There were 16 females 5 males with an average age of $38 \pm 9$ years from our rheumatology outpatient department. All the subjects gave informed consent.

Inclusion criteria: All patients fulfilled the revised American Rheumatic association criteria for rheumatoid arthritis and were free of symptoms of cardiac disease.

Exclusion criteria: Patients with history and /or clinical findings of rheumatic fever, primary cardiomyopathy, congenital heart diseases, and other connective tissue disorders.

Patient evaluation included a complete history, physical examination, ECG, standard echocardiogram. All patients had routine laboratory tests done. The control group constituted 21 volunteers aged $38 \pm 10$ years randomly selected from a group of subjects undergoing routine clinical checkup. These subjects are free of symptoms and signs of cardiac disease. All of them were in sinus rhythm. The two study groups matched for age and sex were compared. RA patients were further grouped according to duration of disease as less than one year and more and compared.

Echocardiographic examination: All echocardiographic evaluations were made in a supine position. A complete echocardiographic examination was done in M-mod and two-dimensional imaging followed by Doppler echo. The ejection fraction of the left ventricle (LVEF) was obtained using Simpson's biplane methods in twodimensional echocardiography [5]. LV end-diastolic dimension (LVD), LV end-systolic dimension (LVS), and left atria dimension (LA) were measured with M-mode echocardiography using a parasternal window.

Doppler echo of mitral inflow was performed with the sample volume placed at the mitral valve tips in the apical 4- chamber view with recording of 5 to 10 cardiac cycles. Using the TDI program, a 5-mm sample volume was placed at the medial corner of the mitral annulus in the 4 - chamber view. Gains were adjusted to eliminate background noise and allow for clear tissue signal; 5 to 10 cycles were then recorded.

The following Doppler parameters were measured: peak of early diastolic (E) and late diastolic (A) flow velocity, E/A ratio, and deceleration time (DT) of flow velocity in early diastole. The following measurements were made from the mitral annular velocity by TDI: early diastolic (Ea) and late diastolic ( $\mathrm{Aa}$ ) velocities and $\mathrm{Ea} / \mathrm{Aa}$ and isovolumetric contraction time (IVCT), isovolumetric relaxation time (IVRT), isovolumetric velocity (IVV), acceleration time (AT), isovolumetric acceleration (IVA). Doppler measurements were averaged over 5 consecutive Cycles.

\section{RESULTS}

Basal clinical parameters like age, pulse rate, blood pressure and ejection fraction is matched between both the groups (Table 1 \& Fig 1).

Table 1. Basic clinical and echocardiographic features

\begin{tabular}{|l|l|l|l|}
\hline PARAMETER & $\begin{array}{l}\text { RA (study } \\
\text { group) }\end{array}$ & Controls & p value \\
\hline Age(years) & $38.38 \pm 10.24$ & $38.5 \pm 9.34$ & 0.96 \\
\hline Pulse Rate(/mt) & $81.81 \pm 11.3$ & $81.05 \pm 10.9$ & 0.779 \\
\hline $\begin{array}{l}\text { Blo.Pre.(Sys } \\
\text { mm of Hg) }\end{array}$ & $128.1 \pm 16.8$ & $128.1 \pm 14.2$ & 1.000 \\
\hline Eje.Fra. (EF) & $65.71 \pm 3.2$ & $66.05 \pm 2.6$ & 0.799 \\
\hline
\end{tabular}

Fig 1: Boxplot of age of controls and RA patients.

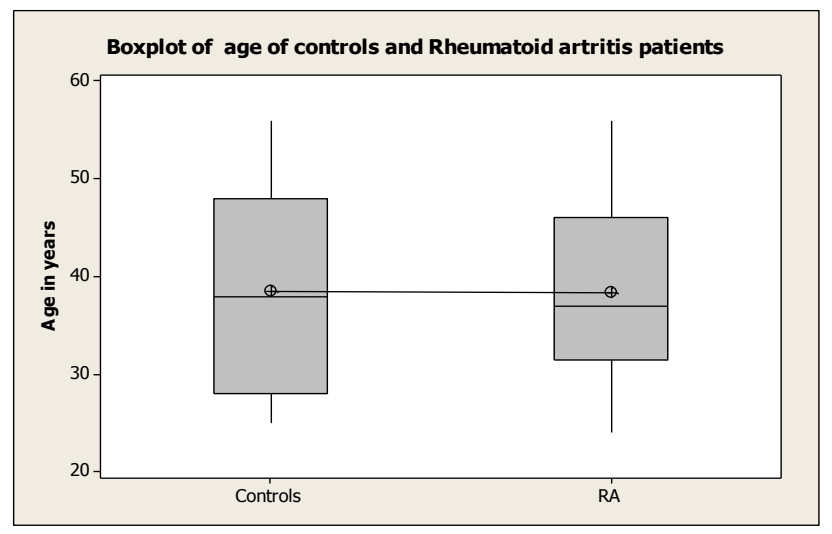


Among conventional Doppler trans valvular mitral flow Parameters E/A ratio was found to be no different in RA patients than that in the control group $(\mathrm{p}=0.77)$. Among TDI parameters, TAPSE, IVCT, IVRT and AT were found to be lower in patient group $(\mathrm{p}<0.001)$, IVV, IVA, $\mathrm{Pm}, \mathrm{Ea}$, and Aa were lower in patient group $(\mathrm{p}<0.001)($ Table 2.)

Table 2: Mitral flow and mitral annular velocities

\begin{tabular}{|l|l|l|l|}
\hline Parameter & RA & Controls & p value \\
\hline E/A & $1.2 \pm 0.15$ & $1.18 \pm 0.25$ & 0.77 \\
\hline TAPSE $(\mathrm{cm})$ & $2.49 \pm 0.18$ & $2.36 \pm 0.22$ & 0.04 \\
\hline IVCT $(\mathrm{msec})$ & $48.8 \pm 11.7$ & $41.5 \pm 7.7$ & 0.02 \\
\hline IVRT(msec) & $82.8 \pm 11.7$ & $76 \pm 10.4$ & 0.05 \\
\hline IVV $(\mathrm{m} / \mathrm{sec})$ & $12.26 \pm 2.23$ & $15.57 \pm 1.89$ & 0.00 \\
\hline Acc.T $(\mathrm{msec})$ & $0.43 \pm 0.05$ & $0.35 \pm 0.05$ & 0.00 \\
\hline IVA $\left(\mathrm{m} / \mathrm{sec}^{2}\right)$ & $28.68 \pm 6.5$ & $45.8 \pm 10.1$ & 0.00 \\
\hline $\mathrm{Pm}(\mathrm{cm} / \mathrm{sec})$ & $12.14 \pm 2.8$ & $12.26 \pm 1.9$ & 0.876 \\
\hline $\mathrm{Ea}(\mathrm{cm} / \mathrm{sec})$ & $10.48 \pm 0.9$ & $13.02 \pm 1.5$ & 0.000 \\
\hline $\mathrm{Aa}(\mathrm{cm} / \mathrm{sec})$ & $9.03 \pm 2.0$ & $11.06 \pm 1.9$ & 0.002 \\
\hline
\end{tabular}

Table 3: Mitral flow and mitral annular velocities in relation to duration of disease

\begin{tabular}{|l|l|l|l|}
\hline Parameter & RA(<1YR) & Controls & $\begin{array}{l}p \\
\text { value }\end{array}$ \\
\hline E/A & $1.17 \pm 0.13$ & $1.21 \pm 0.25$ & 0.57 \\
\hline TAPSE $(\mathrm{cm})$ & $2.46 \pm 0.22$ & $2.35 \pm 0.22$ & 0.24 \\
\hline IVCT(msec) & $50.4 \pm 10.2$ & $41.5 \pm 7.7$ & 0.01 \\
\hline IVRT(msec) & $83.8 \pm 12.9$ & $76 \pm 10.4$ & 0.08 \\
\hline IVV(m/sec) & $12.23 \pm 1.5$ & $15.71 \pm 1.9$ & 0.00 \\
\hline $\mathrm{AT}(\mathrm{msec})$ & $0.43 \pm 0.05$ & $0.35 \pm 0.05$ & 0.00 \\
\hline $\mathrm{IVA}\left(\mathrm{m} / \mathrm{sec}{ }^{2}\right)$ & $28.5 \pm 4.8$ & $45.8 \pm 10.1$ & 0.00 \\
\hline $\mathrm{Ea}(\mathrm{cm} / \mathrm{sec})$ & $10.65 \pm 2.0$ & $13.02 \pm 1.5$ & 0.00 \\
\hline $\mathrm{Aa}(\mathrm{cm} / \mathrm{sec})$ & $8.76 \pm 1.7$ & $11.06 \pm 1.9$ & 0.00 \\
\hline
\end{tabular}

Among conventional Doppler transvalvular mitral flow Parameters E/A ratio was found to be no different in $\mathrm{RA}(<1 \mathrm{YR})$ patients than that in the control group $(\mathrm{p}=$ 0.77). Among TDI parameters, TAPSE, IVCT, IVRT and $\mathrm{AT}$ were found to be lower in patient group $(\mathrm{p}<0.001)$, IVV, IVA, Pm, Ea, Aa were lower in patient group $(\mathrm{p}<0.001)$, in both groups are shown in Table 3 .

In RA patients no significant differences is TAPSE, IVCT, and IVV parameters was found between RA $(<1 \mathrm{yr})$ to RA ( $\geq 1 \mathrm{yr})$ (Table 4$)$.

Table 4: TDI variables and disease duration

\begin{tabular}{|l|l|l|l|}
\hline Parameter & RA $(<1 \mathrm{YR})$ & $\mathrm{RA}(\geq 1 \mathrm{YR})$ & $\mathrm{p}$ value \\
\hline TAPSE $(\mathrm{cm})$ & $2.51 \pm 0.14$ & $2.35 \pm 0.22$ & 0.04 \\
\hline IVCT $(\mathrm{msec})$ & $47.4 \pm 13.2$ & $41.5 \pm 7.7$ & 0.124 \\
\hline $\mathrm{IVV}(\mathrm{m} / \mathrm{sec})$ & $12.06 \pm 2.8$ & $12.23 \pm 1.5$ & 0.869 \\
\hline
\end{tabular}

\section{DISCUSSION}

The main feature of our study was the selection of patients affected by active RA without clinical evidence of heart disease, and their comparison with a control group matched for sex and age. Our results show significant differences between RA patients and the control group in diastolic function of the left ventricle assessed by conventional Doppler echocardiography and TDI, in the absence of systolic abnormalities.LV diastolic dysfunction in patients with RA is usually attributable to common structural abnormalities such as hypertrophy or interstitial fibrosis and impaired myocyte relaxation resulting from ischemia [6]. Mitral flow velocities detected by conventional Doppler echocardiography used for the evaluation of LV diastolic functions are affected by several factors such as heart rate, preload, and afterload. New Doppler parameters have been developed to overcome the limitations in the evaluation of the diastolic functions of mitral flow. One of them is TDI. TDI is a new echocardiographic technique employing the Doppler principle to measure the velocity of myocardial segments and other cardiac structures [7]. Impairment of longitudinal myocardial fiber motion is a sensitive marker of early myocardial dysfunction and ischemia, and TDI might therefore 
become an important tool in routine echocardiography. TDI has a great potential in the diagnosis of diastolic left ventricular dysfunction, overcoming the load dependence of conventional Doppler techniques

In previous studies [8], E, A, and E/A ratio from conventional Doppler trans valvular mitral flow parameters were investigated for the evaluation of $\mathrm{LV}$ diastolic function in patients with RA. From these parameters, E and E/A ratio were found to be different in RA compared with the control group. Our results in regard to these parameters don't go with the previous studies. Five alterations at least seem to be typical of RA patients without any symptom of cardiac disease: Valvular thickening, Pericardial effusion, Aortic root alteration, Aortic valve insufficiency and Left ventricular structural changes. Hence it is possible to represent heart involvement in rheumatoid arthritis as silent rheumatoid heart disease $[9,10]$. Combined circumferential and longitudinal LVSD is detectable in about one fourth of patients with asymptomatic rheumatoid arthritis and is associated with LV concentric remodeling and hypertrophy. Rheumatoid arthritis predicts this worrisome condition, which may explain the increased risk for cardiovascular events in these patients [11]. Almost half of asymptomatic RA patients without history of cardiac disease have subclinical LVSD easily detectable with TDI. RA is closely related to LVSD. A higher degree of LV diastolic dysfunction and systolic blood pressure are associated with LVSD in these patients, whose risk for cardiovascular events could be better defined using such information in the asymptomatic stage of cardiac disease ([2].

From TDI parameters, Em, Em/Am ratio, TAPSE, IVCT, IVRT, AT, IVV, IVA, Pm, Ea and Aa were found tobe lower in RA patients than that in the control group, which supports diastolic dysfunction in patients with RA.This is the first study in literature to use TDI with all its parameters for assessment of diastolic function in patients with RA. In the previous studies using TDI [13] only Em Em/Am ratio was assessed, and the results of this study is concordant with the present study.Our study is the first one to use TDI technique in patients with RA to assess silent cardiac involvement.

\section{CONCLUSION}

Diastolic dysfunction is present even in a patient with rheumatoid arthritis with absolutely no symptoms of cardiac disease. Early detection of this silent killer is beneficial to initiate appropriate treatment. Tissue Doppler echocardiography with all its parameters is far superior for assessment of diastolic dysfunction in patients with RA. Tissue Doppler echocardiography is recommended in all patients with RA for early detection of silent cardiac involvement.

\section{LIMITATIONS}

Study population being very small constitutes marked limitation of the study. Physiological basis of the significant differences in the parameters attained with TDI is not explained. We did not found any relation between the duration of RA, that is less than one year to more than one year, to tissue Doppler abnormalities. This may not be true if RA duration is quite longer, means more than 5 years. But we can say that as early as one year duration of RA also produced the subclinical cardiac involvement which was detected by tissue Doppler imaging. The correlation between tissue Doppler parameters and inflammatory markers was not studied.

\section{REFERENCES}

1. Harris ED. Rheumatoid arthritis. Pathophysiology and implications for therapy. N Engl J Med,1990; 322:1277-1289

2. Mutru $\mathrm{O}$, Laakso $\mathrm{M}$, Isomaki $\mathrm{H}$, Koota $\mathrm{K}$. Cardiovascular mortality in patients with rheumatoid arthritis. Cardiology,1989;76:71-77

3. Lebowits WB. The heart in rheumatoid arthritis. A clinical and pathological study of 62 cases. Ann Intern Med,1963;58:102-123

4. Apstein CS, Eberli FR. Diastolic function and dysfunction with exercise, hypertrophy, ischemia, and heart failure. Cardiologia,1998;43:1269-1279

5. Mandinov L, Eberli FR, Seiler C, Hess OM. Diastolic heart failure. Cardiovasc Res,2000;45:813825 
6. Choong CY, Herrmann HC, Weyman AE, Fifer MA Preload dependence of Doppler-derived indexes of left ventricular diastolic function in humans. J Am Coll Cardiol 1987;10: 800-808.

7. Garcia MJ, Thomas JD, Klein AL. New Doppler echocardiographic applications for the study of diastolic function. J Am Coll Cardiol,1998; 32:865875

8. Lindstrom L, Wranne B. Pulsed tissue Doppler evaluation of mitral annulus motion: a new window to assessment of diastolic function. Clin Physiol,1999;19:1-10

9. Salvatore Corrao. Heart involvement in Rheumatoid Arthritis: Systematic review and metaanalysis International Journal of Cardiology, 2013 Sep 1;167(5):2031-8.

10. Mohammad Bagher Owlia, Cardiac Manifestations of Rheumatological Conditions: A Narrative Review. ISRN Rheumatology Volume 2012 (2012), Article ID 463620. doi: 10.5402/2012/463620. Epub 2012 Oct 17.

11. Cioffi G. Combined Circumferential and Longitudinal Left Ventricular Systolic Dysfunction in Patients with Rheumatoid Arthritis without Overt Cardiac Disease. J Am Soc Echocardiogr. 2016 Feb 24.pii: S0894-7317(16)00005-5.doi: 10.1016/j.echo.2016.01.004.

12. Cioffi G, Prevalence and factors related to left ventricular systolic dysfunction in asymptomatic patients with rheumatoid arthritis. A prospective tissue Doppler echocardiography study. Herz. 2015 Nov;40(7):989-96. doi: 10.1007/s00059-015-4320-5

13. Bruch C, Marin D, Kuntz S, Schmermund A, Bartel T, SchaarJ, Erbel R (1999) Analysis of mitral annulus excursion with tissue Doppler echocardiography (tissue Doppler echocardiography $=\mathrm{TDE}$ ). Noninvasive assessment of left ventricular, diastolic dysfunction. Z Kardiol 88:353-362. 